\title{
Posterior atlanto-occipital and atlanto-axial area and its surgical interest
}

Interesse cirúrgico da junção atlanto-occipital e atlanto-axial

Newton José Godoy Pimenta ${ }^{1,2}$, Sebastião Silva Gusmão ${ }^{3}$, Pierre Kehrli ${ }^{4}$

\begin{abstract}
Classic anatomical studies describe two membranes - atlanto-occipital and atlanto-axial in the posterior aspect of the craniocervical region. During many surgical procedures in this area, however, we have not found such membranes. Objective: To clarify the anatomical aspects and structures taking part of the posterior atlanto-occipital and atlanto-axial area. Method: Analysis of histological cuts of three human fetuses and anatomical studies of 8 adult human cadavers. Results: In both atlanto-occipital and atlanto-axial areas, we have observed attachment between suboccipital deep muscles and the spinal cervical dura. However, anatomical description of such attachments could not be found in textbooks of anatomy. Conclusion: Our study shows the absence of the classical atlanto-occipital and atlanto-axial membranes; the occipito-C1 and C1-C2 posterior intervals are an open area, allowing aponeurotic attachment among cervical dura mater and posterior cervical muscles.
\end{abstract}

Keywords: posterior atlanto-occipital membrane, atlanto-axial area, neurosurgery.

RESUMO

Em livros clássicos de anatomia é referida a existência de duas membranas, atlanto-occipital e atlanto-axial, participando do fechamento da região cranio-cervical. Entretanto, em frequentes procedimentos cirúrgicos que envolvem esta região, jamais detectamos a presença de tais membranas. Objetivo: Estudar os aspectos anatômicos e as estruturas que participam do fechamento posterior dos espaços atlanto-occipital e atlanto-axial. Método: Estudo de cortes histológicos de três fetos humanos e estudos anatômicos em 8 cadáveres humanos adultos. Resultados: Em ambos os espaços, atlanto-occipital e atlanto-axial, encontramos uma aderência entre as estruturas musculares profundas e a dura-mater, sem as membranas atlanto-occipital e atlanto-axial descritas nos livros clássicos de anatomia. Conclusão: Não foram encontradas as membranas atlanto-occipital e atlanto-axial no material estudado; os espaços atlanto-occipital e atlanto-axial são abertos permitindo expansões aponeuróticas entre os músculos profundos e a dura-mater.

Palavras-chave: membrana atlanto-axial posterior, área atlanto-axial, neurocirurgia.

The posterior craniocervical junction is composed of bony and ligamentous structures that together are responsible for biomechanical stability. The atlanto-axial and atlanto-occipital membranes have been described, but their detailed anatomy, histology and biomechanics have not been clarified. This region may be affected by several pathologies, particularly by trauma, tumors and congenital malformations. Thus, a better understanding of its anatomy is essential for surgeons involved in spine care.

The atlanto-occipital and atlanto-axial membranes have been described by many authors ${ }^{1,2}$. Pernkopf and Fick initially questioned this anatomical description, in 1952 and 1904, respectively. They noted that the atlanto-occipital membrane differs from the ligamentum flavum, and that it may be absent in some cases in which the dura mater itself constitutes the sole closing of the atlanto-occipital region.

During surgical procedures involving this area, the authors paid special attention to identifying the different anatomical planes. Surprisingly, we did not find the classical membranes in the deep posterior occipito-cervical region. These observations are in agreement with more recent anatomical studies, which demonstrate that these classical membranes are not part of the closing tissues of this region ${ }^{2,34,5}$.

Our study provides a better understanding of the anatomical aspects of this region's closing structures, as well as their implication in surgical approaches to the occipito-cervical

\footnotetext{
'Surgery, Universite de Sherbrooke, Quebec, Canada;

2Departamento de Neurocirurgia, Faculdade de Medicina, Universidade Federal de Minas Gerais, Belo Horizonte MG, Brazil;

${ }^{3}$ Departamento de Cirurgia, Faculdade de Medicina, Universidade Federal de Minas Gerais, Belo Horizonte MG, Brazil;

${ }^{4}$ Neurosurgery, Hospital Hautepierre, Alsace, France.

Correspondence: Newton José Godoy Pimenta; Rua Tenente Garro, 101 / ap. 104; 30240-360 Belo Horizonte MG; Brasil; E-mail: newtongodoy@hotmail.com Conflict of interest: There is no conflict of interest to declare.

Received 26 December 2013; Received in final form 24 July 2014; Accepted 13 August 2014.
} 
region. To the best of our knowledge, ours is the only study that uses fresh cadavers and histological observations in human fetuses.

\section{METHOD}

\section{Study design}

For the last five years, we have been observing and documenting, with microscopic photos and videos, the anatomical disposition of the elements involved in closing the posterior atlanto-occipital and atlanto-axial spaces, as well as the anatomical relationship of deep muscles and their fascia to spinal dura mater. The subjects were patients who underwent posterior fossa and craniocervical surgery. In our surgical observations, we were unable to identify the posterior membranes in the atlanto-occipital and atlanto-axial spaces. We speculated that the anatomical changes caused by pathologies involving the craniocervical junction could modify ordinary anatomy. To clarify our observations, we performed the histological and anatomical studies, as follows.

\section{Histological study}

We examined $10-\mu \mathrm{m}$ thick serial sections at the Institut d'Anatomie Normale de Strasbourg, France. These sections, in different anatomical planes, were taken from three human fetal cadavers ${ }^{6}$.

\section{Anatomical study}

Eight fresh adult cadavers, whose ages varied between 57 and 90 years, were prepared for dissection at the Institute of Anatomy at the University of Sherbrooke, Canada. None had a traumatic cause of death (Table).

The body was placed in the ventral position and the craniocervical junction was prepared for dissection. The skin, superficial fascia and superficial muscles over the posterior neck region were incised, and the occipital bone, $\mathrm{C} 1$ and $\mathrm{C} 2$ were exposed, providing access to the suboccipital muscles. The relation between the spinal dura mater and posterior components of the vertebral canal were exposed and

Table. Characteristics of the fresh adult cadavers

\begin{tabular}{lccc}
\hline $\begin{array}{l}\text { Identification of } \\
\text { the cadavers }\end{array}$ & Age (years) & Sex & Cause of death \\
\hline 1-F-25-13 & 77 & Women & Myocardial infacrtion \\
$2-$ F-30-13 & 66 & Men & Lung cancer \\
3-F-29-13 & 57 & Men & Intestinal cancer \\
4-F-31-13 & 65 & Men & Intestinal cancer \\
$5-$ F-24-13 & 90 & Women & Aort dissection \\
6-F-32-13 & 61 & Men & Laryngeal canver \\
$7-$ F-22-13 & 74 & Women & Myocardial infarction \\
8-F-28-13 & 66 & Men & Myocardial infarction \\
\hline
\end{tabular}

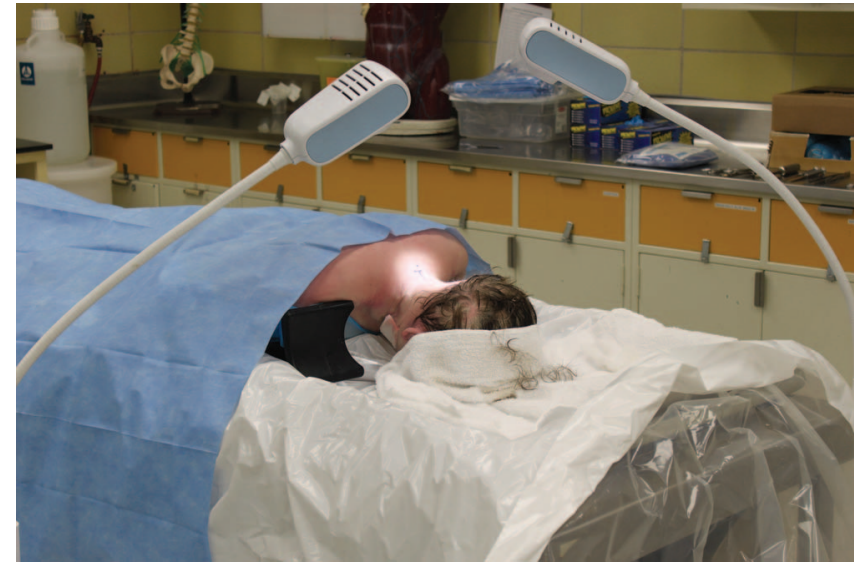

Figure 1. Photo that show de ventral position of the cadavers before de dissection, similar to a surgical approach.

recorded by digital images taken with a LEICA M320 microscope with a magnification of 6.4x (Figure 1).

\section{RESULTS}

\section{Atlanto-occipital space}

This region is situated between the occipital bone and the first cervical vertebra (C1). During histological preparations, we observed that the anterior fascia of the rectus capitis posterior minor (RCPm) muscle was not completely attached to the posterior border of $\mathrm{C} 1$, as classically described. An anterior expansion of the RCPm fascia, detached from the anterior aspect of the muscle, passes through a space filled with loose connective and adipose tissue, before attaching itself to the spinal dura mater (Figure 2).

The anatomical study provided the same results. Under microscopic view, the first observation pointed to the absence of a unique atlanto-occipital membrane. We can observe the dura mater without further dissection or opening the space (Figure 3).

All the dissections and histological observations confirmed the absence of the atlanto-occipital membrane in the atlanto-occipital space, and suggested a new finding: the existence of a myodural attachment between the $\mathrm{RCPm}$ and the dura mater (Figure 4).

\section{Atlanto-axial space}

The atlanto-axial space is situated between the posterior arch of $\mathrm{C} 1$ and the posterior arch of $\mathrm{C} 2$. The rectus capitis posterior major and oblique inferior muscles dorsally cover it.

During our histological preparations, we observed that the anterior fascia of the rectus capitis posterior major (RCPma) muscle was not completely attached to the posterior border of $\mathrm{C} 2$, as classically described. An anterior expansion of the fascia of the RCPma, detached from the anterior 


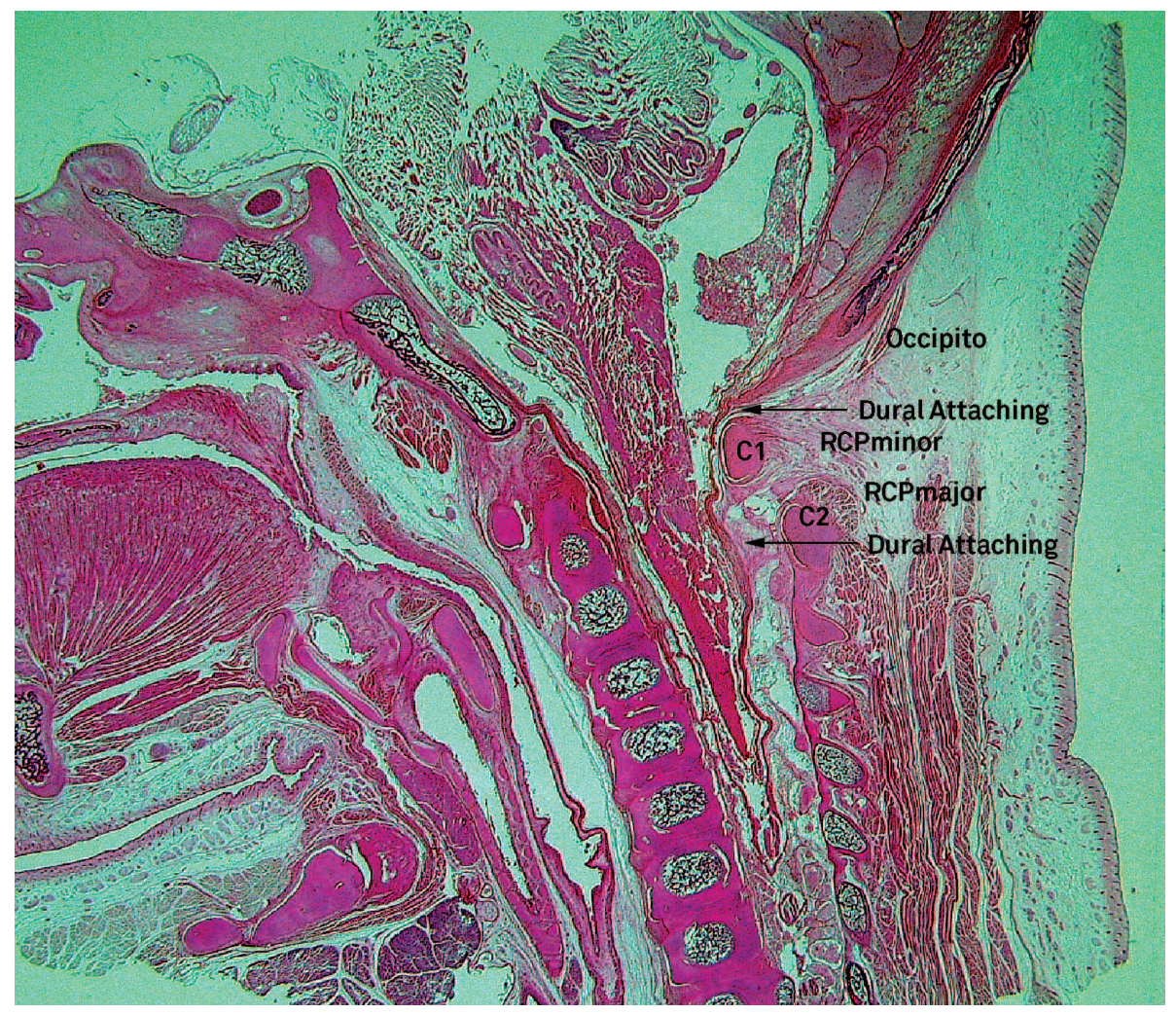

Figure 2. Histological sagital cut of a human fetus.

aspect of the muscle, passes through a space filled with loose connective and adipose tissue, before attaching itself to the spinal dura mater (Figure 2).

The anatomical study showed the same findings. Under microscopic view, the first observation pointed to the absence of a unique atlanto-axial membrane. We can observe the dura mater without further dissection or opening in this space. As in the atlanto-occipital space, we found a myodural attachment between the RCPma and the dura mater (Figure 5).

All the dissections and histological observations confirmed the absence of the atlanto-axial membrane and also

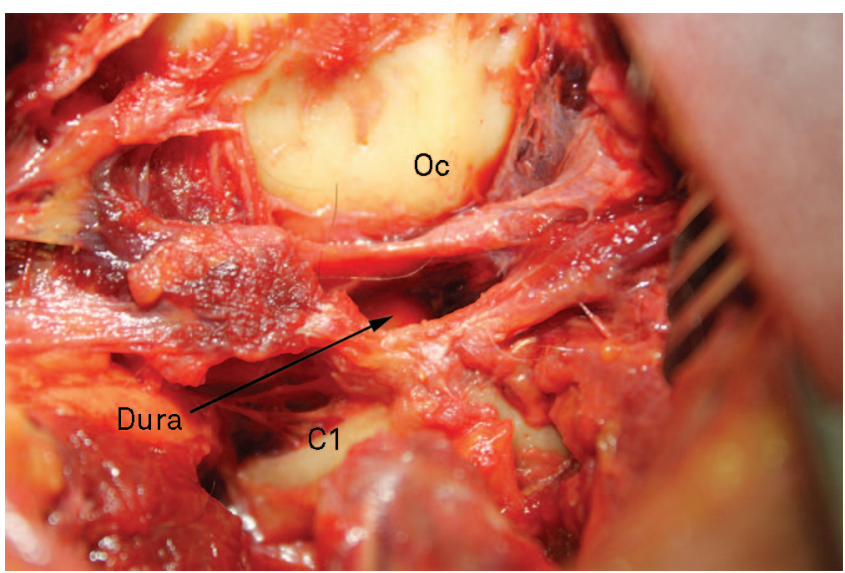

Figure 3. Microscopic view showing to the absence of a unique atlanto-occipital membrane and the direct view of the dura. suggested the existence of a myodural attachment between the RCPma and the dura mater (Figure 5).

\section{DISCUSSION}

The interest in conducting this study was to observe the anatomical constitution of the occipito-cervical region, as well as to evaluate the role these spaces play in surgical procedures.

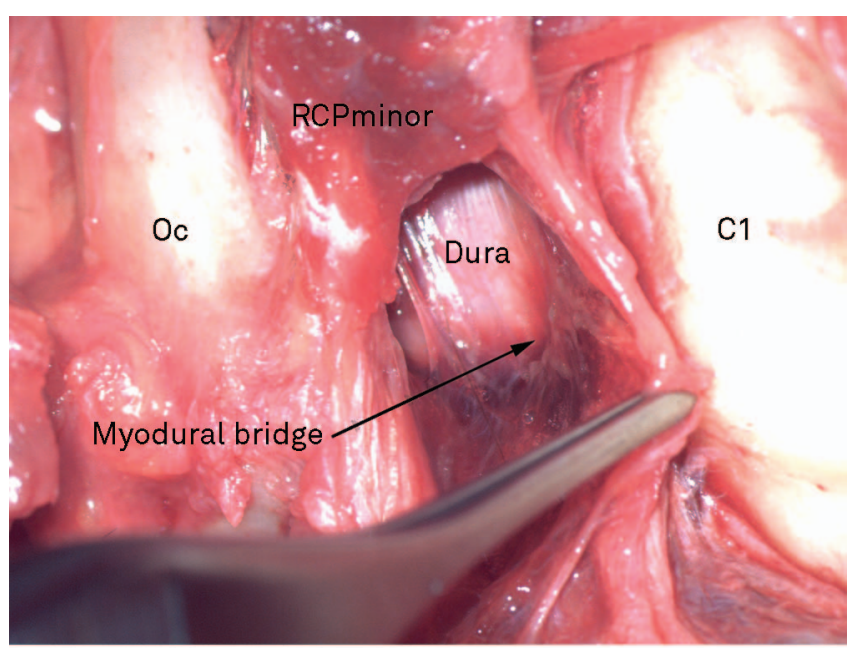

RCPm : Rectus capitis poterior minor

Figure 4. Microscopic view showing RCPm laterally and its atachment on the dura (myodural bridge). 


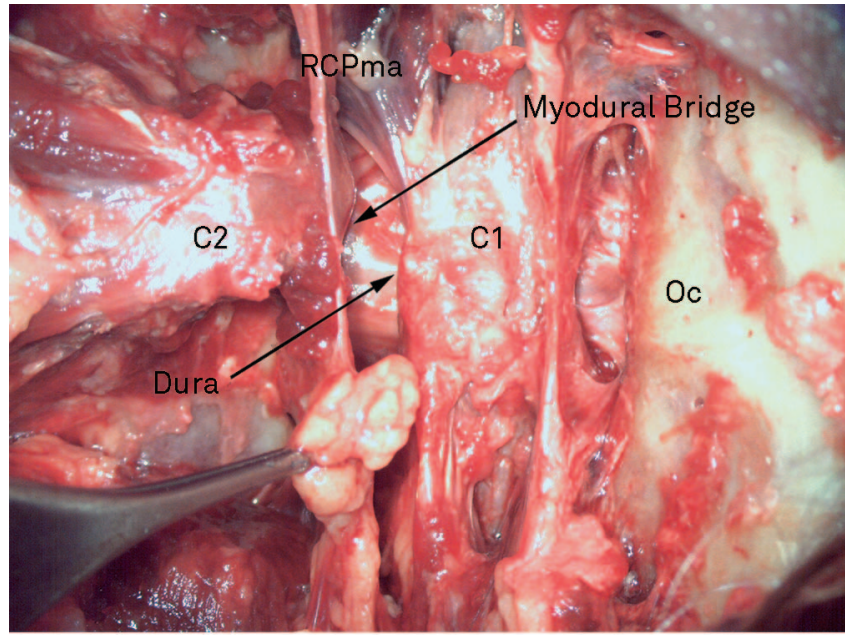

$\mathrm{RCP}$ : Rectus capitis posterior

Figure 5. Microscopic view showing the absence of a unique atlanto axial membrane and the direct view of the dura RCPmajor laterally and its atachment on the dura (myodural bridge).

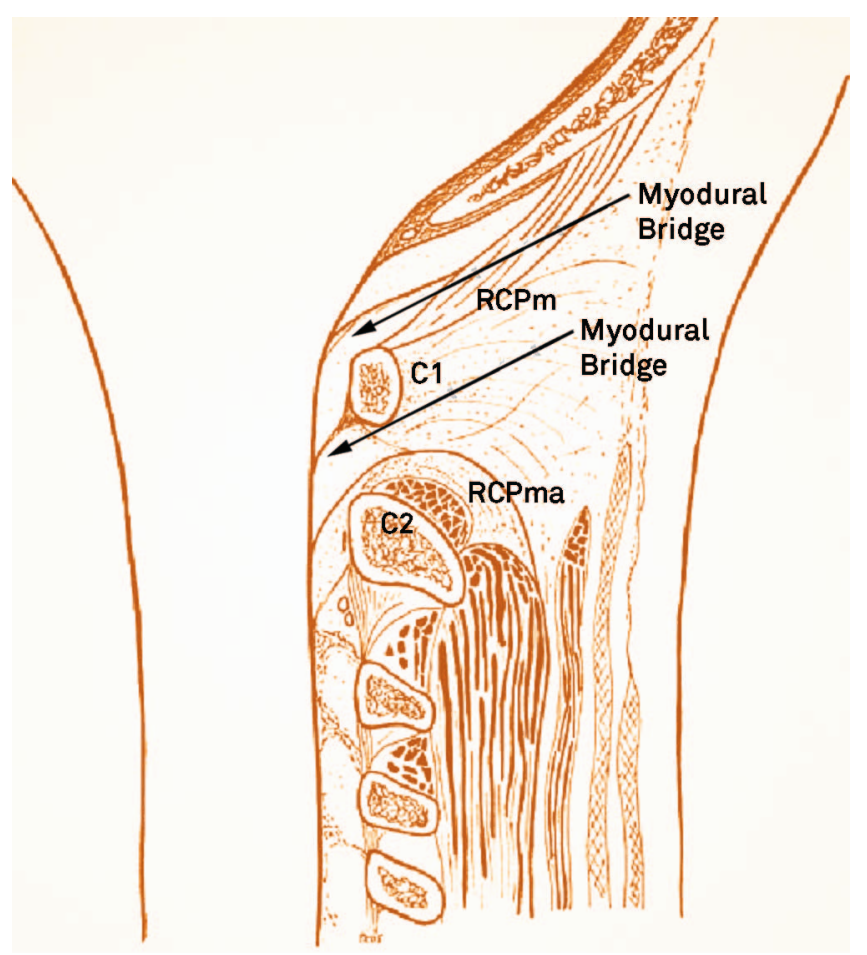

Figure 6. Esquematic representation of authors anatomical proposition.

In classical anatomy books, the atlanto-occipital and alanto-axial membranes are described as thin membranes between the atlanto-occipital and atlanto-axial spaces ${ }^{1}$.

Based on our findings, we propose a new description of the anatomical constitution of the covering structures of the posterior cranio-vertebral space (Figure 6). Instead of the classical membranes, thin expansions of some muscular fascia descend directly to the dura mater. These findings are in agreement with the first description of the atlanto-occipital level by Kahn et al. ${ }^{3}$ and further corroborated by Hack et al. ${ }^{7}$ and Scali et al., ${ }^{2,5}$.

At the C1-C2 level, our observations differed from the reports of Mitchell et al. ${ }^{8}$ and Dean and Mitchell ${ }^{9}$ that described an attachment of the ligamentum nuchae to the cervical posterior dura mater. We were unable to identify any kind of communication between the ligamentum nuchae and dura mater.

In 1992, Khan et al. ${ }^{3}$ conducted a study on the posterior intervertebral spaces of the craniovertebral junction and observed the absence of the atlanto-axial membrane. Pimenta and cols. ${ }^{4}$, in an anatomical study, observed the absence of the atlanto-occipital and atlanto-axial membranes in five embalmed preparations of the occipitocervical regions. In 2011, Scali and cols. published another anatomical study with 13 embalmed specimens fixed in formalin and confirmed the absence of the atlanto-axial membrane between $\mathrm{C} 1$ and $\mathrm{C} 2$ spaces. Two years later, the same author performed a histological study and described the existence of attachments between RCPma and the dura mater at C1-C2 space $^{5,10}$.

One criticism of the previous anatomical study's use of embalmed cadavers was the possibility that the solution used to fix the specimens could produce some degree of degeneration and such thin membranes would therefore not be observed.

In order to avoid any degeneration, we did not use solutions and all dissections were performed on fresh cadaveric specimens.

Our results allow us to conclude that, even in the early stages of human embryological development, and also in fresh cadavers, the atlanto-occipital and atlanto-axial membranes were absent and connections between the RCPm and RCPma with the dura mater can be seen.

However, the exact role played by those muscle expansions and their connections with the dura mater has not yet been fully understood. In such a flexible area, muscle expansions may, for instance, ensure adequate tension of the dura during the performance of complex movements.

One hypothesis speculated by the authors is that the connective tissue areas could be interpreted as an adaptation of the vertebra, muscle and dura mater to movement. Moreover, adipose tissue, also known for favouring movement (it has lubricating properties and the venous plexus system prevents painful traction or friction), was found on the described epidural space. It was also noted that in the rostral end of the posterior epidural space, the two membranes disappear and are replaced by loose connective spaces, a fact that the authors could not correlate with a specific function.

Connective bridges between muscles and the dura mater also constitute a passage for nervous fibres. Although this 
situation has not been described at the posterior occipitocervical region, it was recently described as a connection between dura mater and posterior longitudinal ligament ${ }^{11}$. Alix and Bates ${ }^{12}$ proposed this anatomical disposition as a possible etiology of cervicogenic headache.

The anatomical disposition of the craniocervical junction structures should be better studied to minimize surgical complications. The proper anatomical knowledge should help to:

- Localize and avoid the venous plexus in the superior area of the atlanto-occipital region;

- Determine the avascular space between the C1 and C2 arches;
- Avoid traction of the dura mater when removing the posterior arch of $\mathrm{Cl}$; and

- Locate and prevent injuries on the upper part of the epidural plexus.

In conclusion according to the histological and anatomical observations set out above, we demonstrated the absence of the classical atlanto-occipital and atlanto-axial membranes in histological fetal observations and in fresh cadaver dissections. Thus, the occipito-C1 and C1-C2 intervals, in our study design, constitute an open area, allowing aponeurotic expansions to attach to the cervical dura mater.

\section{References}

1. Rouvière H. Anatomie humaine. In: Delmas A, editor. 11th ed. Vol. 1, Tête et cou. Paris: Masson; 1981. Articulations des vertèbres cervicales. p. 138-40.

2. Soames RW. The skeletal system. In: Williams PL, editor. Gray's anatomy. 38th ed. Oxford: Churchill Livingstone; 1995. p. 512-5.

3. Kahn JL, Sick H, Koritké JG. Les espaces intervertébraux postérieurs de la jointure crânio-rachidienne. Acta Anat. 1992;144(1):65-70. http://dx.doi.org/10.1159/000147287

4. Pimenta NJG, Pinheiro-Franco JL, Gonçalves MB, Esposito P, Avellar L, Kehrli P. Posterior atlanto-occipital and atlanto-axial spaces of the craniovertebral regions and their surgical interest [abstract]. Eur Spine J. 2005;14(Suppl 1):S75. (Presented at 7th Annual Meeting of the Spine Society of Europe; 2005; Barcelona, Spain]. http://dx.doi. org/10.1007/s00586-005-0997-0

5. Scali F, Maiseli ES, Pontel ME. Anatomical connection between the rectus capitis posterior major and the dura mater. Spine. 2011;36(25):E1612-14. http://dx.doi.org/10.1097/BRS.0b013e31821129df

6. Kehrli P, Ali M, Reis M, Maillot C, Dietermann JL, Dujovny M, Ausman $\mathrm{Jl}$. Anatomy and embryology of the lateral sellar compartment (cavernous sinus) medial wall. Neurol Res. 1998;20(7):585-92.
7. Hack GD, Koritzer RT, Robinson WL, Hallgreen REC, Greenman PE. Anatomical relation between the rectus capitis posterior minor muscle and dura mater. Spine. 1995;20(23):2484-6.

8. Mitchell BS, Humphreys BK, O'Sullivan E. Attachments of the ligamentum nuchae to cervical posterior spinal dura and the lateral part of the occipital bone. J Manipulative Physiol Ther. 1998;21(3):145-8.

9. Dean NA, Mitchell BS. Anatomic relation between the nuchal ligament (ligamentum nuchae) and the spinal dura mater in the craniocervical region. Clin Anat. 2002;15(3):182-5. http://dx.doi.org/10.1002/ca.10001

10. Scali F, Pontell ME, Enix DE, Marshall E. Histological analysis of the rectus capitis posterior major's myodural bridge. Spine J. 2013;13(5):558-63. http://dx.doi.org/10.1016/j.spinee.2013.01.015

11. Kumar R, Berger RJ, Dunsker SB, Keller JT. Innervation of the spinal dura. Myth or reality? Spine. 1996;21(1):18-26. http://dx.doi.org/ 10.1097/00007632-199601010-00004

12. Alix ME, Bates DK. A proposed etiology of cervicogenic headache: the neurophysiologic basis and anatomic relationship between the dura mater and the rectus posterior capitis minor muscle. J Manipulative Physiol Ther. 1999;2298):534-9. http://dx.doi.org/ 10.1016/s0161-4754(99)70006-0 